\title{
Proteomic Profiling of Neuroblastoma Cells Adhesion on Hyaluronic Acid-Based Surface for Neural Tissue Engineering
}

\author{
Ming-Hui Yang, ${ }^{1}$ Ko-Chin Chen, ${ }^{2}$ Pei-Wen Chiang, ${ }^{3}$ Tze-Wen Chung, \\ Wan-Jou Chen, ${ }^{3}$ Pei-Yu Chu, ${ }^{5,6}$ Sharon Chia-Ju Chen, ${ }^{3}$ Yi-Shan Lu, ${ }^{7}$ \\ Cheng-Hui Yuan, ${ }^{8}$ Ming-Chen Wang, ${ }^{9}$ Chia-Yang Lin, ${ }^{3,10}$ Ying-Fong Huang, ${ }^{3,10}$ \\ Shiang-Bin Jong, ${ }^{3,10}$ Po-Chiao Lin, ${ }^{11}$ and Yu-Chang Tyan ${ }^{1,3,12,13}$ \\ ${ }^{1}$ Center for Infectious Disease and Cancer Research, Kaohsiung Medical University, Kaohsiung 807, Taiwan \\ ${ }^{2}$ Department of Pathology, Changhua Christian Hospital, Changhua 500, Taiwan \\ ${ }^{3}$ Department of Medical Imaging and Radiological Sciences, Kaohsiung Medical University, Kaohsiung 807, Taiwan \\ ${ }^{4}$ Department of Biomedical Engineering, National Yang-Ming University, Taipei 112, Taiwan \\ ${ }^{5}$ Department of Laboratory Medicine, Kaohsiung Medical University Hospital, Kaohsiung 807, Taiwan \\ ${ }^{6}$ Department of Medical Laboratory Science and Biotechnology, College of Health Sciences, Kaohsiung Medical University, \\ Kaohsiung 807, Taiwan \\ ${ }^{7}$ Office of Safety, Health and Environment, Kaohsiung Medical University, Kaohsiung 807, Taiwan \\ ${ }^{8}$ Mass Spectrometry Laboratory, Chemical, Molecular and Materials Analysis Center, Department of Chemistry, \\ National University of Singapore, Singapore 119077 \\ ${ }^{9}$ Department of Biomedical Engineering, Chung Yuan Christian University, Chungli 300, Taiwan \\ ${ }^{10}$ Department of Nuclear Medicine, Kaohsiung Medical University Hospital, Kaohsiung 807, Taiwan \\ ${ }^{11}$ Department of Chemistry, National Sun Yat-sen University, Kaohsiung 804, Taiwan \\ ${ }^{12}$ Graduate Institute of Medicine, College of Medicine, Kaohsiung Medical University, Kaohsiung 807, Taiwan \\ ${ }^{13}$ Institute of Medical Science and Technology, National Sun Yat-sen University, Kaohsiung 804, Taiwan
}

Correspondence should be addressed to Yu-Chang Tyan; yctyan@kmu.edu.tw

Received 27 June 2016; Revised 10 September 2016; Accepted 5 October 2016

Academic Editor: Pornanong Aramwit

Copyright (C) 2016 Ming-Hui Yang et al. This is an open access article distributed under the Creative Commons Attribution License, which permits unrestricted use, distribution, and reproduction in any medium, provided the original work is properly cited.

\begin{abstract}
The microenvironment of neuron cells plays a crucial role in regulating neural development and regeneration. Hyaluronic acid (HA) biomaterial has been applied in a wide range of medical and biological fields and plays important roles in neural regeneration. PC12 cells have been reported to be capable of endogenous NGF synthesis and secretion. The purpose of this research was to assess the effect of HA biomaterial combining with PC12 cells conditioned media (PC12 CM) in neural regeneration. Using SH-SY5Y cells as an experimental model, we found that supporting with PC12 CM enhanced HA function in SH-SY5Y cell proliferation and adhesion. Through RP-nano-UPLC-ESI-MS/MS analyses, we identified increased expression of HSP60 and RanBP2 in SHSY5Y cells grown on HA-modified surface with cotreatment of PC12 CM. Moreover, we also identified factors that were secreted from PC12 cells and may promote SH-SY5Y cell proliferation and adhesion. Here, we proposed a biomaterial surface enriched with neurotrophic factors for nerve regeneration application.
\end{abstract}

\section{Introduction}

Nerve injury is an important topic in the world of medicine and there are many nerve injury cases reported every year. These injuries usually have caused a decreased quality of life because of reduction in motor, sensory and autonomic functions $[1,2]$. The peripheral nervous system is more permissive to axonal regeneration then the central nervous system; but it is still a challenge to surgery [3]. Despite microsurgical techniques which are more advanced, experimental 
and clinical evidences show the results of peripheral nerve recovery are not satisfying $[4,5]$. Nerve autograft is the gold standard technique for therapy in peripheral nerve injury. A tubular nerve guidance channel is necessary for nerve autograft. It acts as a physical guide for nerve regeneration and provides a conduit for neurotrophic factor diffusion from the injured nerve stumps $[3,6,7]$. In the past few years, scientists have focused on various conduit materials, including aliphatic polyesters [8, 9], poly(phosphoesters) [10], polyurethanes [11], piezoelectric polymers [12], hydrogelbased nerve guide channels [13], collagen [14], polysaccharides [15], and decellularized biomatrices $[3,16]$.

Hyaluronan (hyaluronic acid, HA), a component of the extracellular matrix, is a glycosaminoglycan applicable to biomaterial. During embryogenesis, the concentration of HA is at the peak in undifferentiated cells and decreases at the beginning of cell differentiation [17]. Such change is crucial for the angiogenic process regulation and its presence in the extracellular matrix (ECM) is as a naturally occurring polysaccharide [18-20]. HA is vital in the brain development, especially to the postnatal brain in regions adjacent to the lateral ventricles where stem cells reside [21, 22]. It has been reported as a significant factor in a wide range of medical and biological fields, such as reactive oxygen species, angiogenesis, cancer, lung injury, liver injury, kidney injury, brain injury, diabetes, and leukocyte trafficking and in immune regulation $[23,24]$. It also plays important roles in neural proliferation, differentiation, migration, survival, and cell signaling [25]. HA-induced signal transduction depends on the interactions of cell surface receptors, including cluster determinant 44 (CD44) and toll-like receptor 4 (TLR4) [26]. In the central nervous system, the HA expression level is elevated at damaged sites. The high molecular weight HA has been digested through hyaluronidases becoming smaller fragments; such products activate downstream signal transduction to regulate progenitor cell differentiation and proliferation to promote nerve repair [25]. It also has advantages as a scaffold material and can be combined with adhesive peptides or other ECM components to provide cell attachment. Previous study indicated that combination scaffolds consisting of fibrin with HA and laminin provide biomaterial properties to enable polymerization with cells. This mimics the native tissue of the brain and supports differentiation of human neural stem/progenitor cell (hNSPC) function [27]. Currently, HA-based biomaterials are used to regulate the cell differentiation and studied for tissue engineering purposes in combination with growth factors or ECM components for tissue repair [28-33].

Cell to cell interaction is important for cell fate determination, providing the first evidence for short-range regulatory mechanisms of cell differentiation. The conditioned medium $(\mathrm{CM})$, which contains growth factors and differentiation regulation factors that are released from the cultured cells, could be used to promote cell differentiation into specific lineages [34]. Previous reports indicated that mouse embryonic stem cells (mESCs) treated with HepG2 CM can enhance mesoderm induction and the subsequent osteogenic differentiation of mESCs [35]. In addition, human marrow stromal cells (hMSC) CM can stimulate the induction of the mesodermal lineage and subsequent differentiation toward the osteogenic and chondrogenic lineage [36]. Differentiation of the human umbilical cord blood neuronal progenitors (HUCBNPs) was achieved by treatment with human SHSY5Y CM, which showed an increase of the ratio of long outgrowths to cell body diameter and a characteristic of developing neurons [37]. PC12 cells require no supplementary NGF for survival and proliferation because they synthesize and secrete endogenous NGF into the medium as an autocrine regulation, which may be applied for neuron development [38]. The combination of PC12 CM and HA surface biomaterials may synergistically induce the neuronal cell differentiation, offering a new field of vision in nerve regeneration.

In this study, we examined the effects of $\mathrm{HA}$ and PC12 CM in SH-SY5Y cells. SH-SY5Y is one kind of human derived cell line which is used in scientific research. The original cell line, called SK-N-SH, was subcloned and isolated from a bone marrow biopsy, which had been taken from a female with neuroblastoma. This cell line has been widely used as a model of neuron diseases as these cells possess many biochemical and functional properties of neurons. SH-SY5Y cells have been widely used as in vitro models of neurological studies, including analysis of neuronal differentiation, metabolism, and function related to neurodegenerative and neuroadaptive processes, neurotoxicity, and neuroprotection. It can be differentiated to a more mature neuron-like phenotype that is characterized by dopaminergic markers and, as such, has been used to study Parkinson's disease [39]. Through the investigation, proteins that influence the responses and later proliferation of SH-SY5Y cells on HA-biopolymer surfaces and PC12 CM were identified. Using proteomic approaches to assess characteristic proteins from $\mathrm{HA}$ and PC12 CM treatment found that heat shock protein 60 (HSP60) and E3 SUMO-protein ligase RanBP2 were involved in cell proliferation and attachment regulated the UBC/PI3K/AKT1/mTOR pathway.

\section{Materials and Methods}

2.1. HA Surfaces Determined by QCM Measurements. The surface of a $9 \mathrm{MHz}$ QCM gold electrode (ANT Tech, Taiwan) was washed with $1 \mathrm{M} \mathrm{HCl}$, rinsed with DI water, followed by drying at room temperature. The frequency of the electrode measured by the QCM (ADS, ANT Tech, Taiwan) was assigned as $F_{0}$ and the flow rate was $60 \mu \mathrm{L} / \mathrm{min}$ of phosphate buffered saline (PBS). To prepare QCM-HA layers, HA was adsorbed onto a QCM electrode surface using the layer-bylayer technique. The HA solution (0.5\%, Lifecore Biomedical, Inc., USA) was injected into the flow loop of the QCM electrode at flow rate of $60 \mathrm{~mL} / \mathrm{min}$ and the frequency shifts of the QCM were measured. The frequency shifts determined by the QCM were recorded and the mass of HA adsorption was calculated. To test whether HA layer is stably coated onto the electrode, the frequency of the electrode was measured by the flow of PBS for several minutes. For tested HA-biopolymer, the frequency shift dropped sharply, it was absorbed onto the electrode surface. The detection theory for QCM can be 
explained by the Sauerbrey equation (1), which calculates that the mass change is proportional to the oscillation frequency shift of the piezoelectric quartz crystal.

$$
\Delta F=-2.3 \times 10^{-6} \frac{F^{2} \Delta M}{A}
$$

In Sauerbrey equation (1) in gas phase, $\Delta F$ is the frequency shift $(\mathrm{Hz}) ; F$ is basic oscillation frequency of piezoelectric quartz $(\mathrm{Hz}) ; A$ is the active area of QCM $\left(\mathrm{cm}^{2}\right) ; \Delta M$ is the mass change on QCM (g).

2.2. Culturing SH-SY5Y Cells on the Electrodes Decorated by HA Surfaces. For seeding SH-SY5Y cells, the HA-modified electrodes, decorated by biopolymer layers, were sterilized with $70 \%(\mathrm{v} / \mathrm{v})$ ethanol and then exposed to ultraviolet light. The $4 \times 10^{4} \mathrm{SH}-\mathrm{SY} 5 \mathrm{Y}$ cells in serum-free medium were added to each well in the presence of the aforementioned electrodes and incubated at $37^{\circ} \mathrm{C}$ in $5 \% \mathrm{CO}_{2}$ for 12 hours for investigation of the adhesion of the cells on those electrodes. After the incubations, the electrodes were washed with PBS, and then frequency shifts were measured by the QCM to quantify the adhesions of SH-SY5Y cells on electrodes.

2.3. HA Surface Characterized by FT-IR. The surface characterization of the coverslips decorated with HA was observed using a Fourier transform infrared spectrometer (FT-IR, Spectrum One system, PerkinElmer, USA).

2.4. Cell Culture and Conditioned Media (CM) Collection. For human neuroblastoma cell line, SH-SY5Y cells were cultured in Dulbecco's Modified Eagle Medium: nutrient mixture F12 (DMEM/F12) medium (Gibco, Invitrogen, USA) with 10\% FBS plus $1 \%$ antibiotics. In the pheochromocytoma cell line of the rat adrenal medulla, PC12 cells were maintained in DMEM medium with $10 \%$ horse serum, 5\% FBS plus $1 \%$ antibiotics. Those cells were incubated in $5 \% \mathrm{CO}_{2}$ at $37^{\circ} \mathrm{C}$ for 48 hours.

In this study, PC12 CM were collected, filtered, and mixed with equal volumes of fresh DMEM/F12 medium for SHSY5Y cells to be cultivated on HA surface. To collect PC12 $\mathrm{CM}$, the PC12 cells were rinsed with phosphate buffer saline (PBS) and then incubated in serum-free DMEM medium for 12 hours. Then, the supernatants of the medium were collected and filtered with $0.22 \mu \mathrm{m}$ filter.

2.5. Protein Preparation for Proteomic Analysis. SH-SY5Y cell lysates or PC12 CM were transferred into $1.5 \mathrm{~mL}$ tubes and reduced with $1 \mathrm{M}$ dithiothreitol (DTT, USB Corporation, USA) in $25 \mathrm{mM} \mathrm{NH}_{4} \mathrm{HCO}_{3}$ at $37^{\circ} \mathrm{C}$. After 3 hours, protein samples were alkylated with $1 \mathrm{M}$ iodoacetamide (IAA, Amersham Biosciences, USA) in the dark at room temperature for $30 \mathrm{~min}$. After the proteins were digested by sequencing-grade modified porcine trypsin (Promega, USA) overnight at $37^{\circ} \mathrm{C}$, $2 \mu \mathrm{L}$ of formic acid was added to each sample.

RP-nano-UPLC ESI-MS/MS analyses (nanoACQUITY UPLC, Waters, Milford, MA, coupled to an ion trap mass spectrometer, LTQ Orbitrap Discovery Hybrid FTMS,
Thermo, San Jose, CA) were conducted according to standard procedures described below. Briefly, a sample of the desired peptide digest was loaded into the reverse phase column (symmetry C18, $5 \mu \mathrm{m}$, and $180 \mu \mathrm{m} \times 20 \mathrm{~mm}$ ). The RP separation was performed using a linear acetonitrile gradient from $99 \%$ buffer A (100\% DI water/0.1\% formic acid) to $85 \%$ buffer B (100\% acetonitrile/ $0.1 \%$ formic acid) in $120 \mathrm{~min}$ using the micropump at a flow rate of approximately $400 \mathrm{~nL} / \mathrm{min}$. The separation was performed on a C18 microcapillary column (BEH C18, $1.7 \mu \mathrm{m}$, and $75 \mu \mathrm{m} \times 100 \mathrm{~mm}$ ). As peptides were eluted from the microcapillary column, they were electrosprayed into the ESI-MS/MS with the application of a distal $2.1 \mathrm{kV}$ spraying voltage with heated capillary temperature of $200^{\circ} \mathrm{C}$. Each cycle of one full-scan mass spectrum $(\mathrm{m} / z 400-$ 2000) was followed by three data dependent tandem mass spectra with collision energy set at 35\% [40].

All MS and MS/MS data were analyzed and processed using the Mascot software (Version 2.2.1, Matrix Science, London, UK) against the Swiss-Prot database. The search parameters were set as follows: $0.5 \mathrm{Da}$ for $\mathrm{MS} / \mathrm{MS}$ tolerance, $10 \mathrm{ppm}$ for MS tolerance, carbamidomethylation (C) as the fixed modification, deamidated (NQ), oxidation (M), phospho (ST) and phospho (Y) as the variable modification, and 2 for missing cleavage. Proteins were initially annotated by similar search conditions using UniProtKB/Swiss-Prot databases (SIB Swiss Institute of Bioinformatics, Lausanne, Switzerland). The protein-protein interaction pathways were performed by String 9.1 Web software (SIB Swiss Institute of Bioinformatics, Lausanne, Switzerland) [41].

2.6. Western Blotting of Protein Expression. Confirmation of protein identities was performed by Western blotting. Protein extracts were prepared in lysis buffer and each cell lysate sample $(1 \mu \mathrm{g} / \mu \mathrm{L}, 10 \mu \mathrm{L})$ was electrophoresed through a precast gel (NuPAGE ${ }^{\circledR}$ Novex $^{\circledR}$ 4-12\% Bis-Tris Gel, 1.5 mm, 10 wells, Invitrogen $^{\mathrm{TM}}$, Carlsbad, CA). Proteins were transferred from the gel to a polyvinyldifluoride (PVDF) membrane (Millipore, Bedford, CA) by means of the semidry technique using the Criterion Blotter (Bio-Rad) at $100 \mathrm{~V}$ for $60 \mathrm{~min}$ and blocked with 5\% milk in PBS (adjusted to $\mathrm{pH} 7.4$ ) containing $0.05 \%$ Tween-20. The membranes were then separately incubated overnight with primary rabbit antibodies $(1 \mu \mathrm{g} / \mu \mathrm{L})$. The commercially available primary antibodies used in this study included the following: monoclonal mouse anti-HSP60 (Stressgen, USA) and polyclonal rabbit anti-RanBP2 (Abcam, USA). After washing, the membrane was incubated with HRP-conjugated goat anti-mouse IgG antibodies (purchased from Jackson ImmunoResearch, USA) for 1 hour (1:10000). Proteins were detected with an enhanced chemiluminescent (ECL) system, and quantitative analysis of Western blotting was carried out using the ImageQuant-TL-7.0 software, version 2010 (Amersham Biosciences).

2.7. BrdU Assay. The cell viability was determined by BrdU cell proliferation assay kit (Millipore). The assay was performed according to the manufacturer's instructions. Briefly, $1 \times 10^{3} \mathrm{SH}-\mathrm{SY} 5 Y$ cells were seeded in a sterile 96-well tissue culture plate and incubated for 24 to 72 hours. Then, cells were 
incubated in the culture medium containing BrdU reagent for 2 hours. Fixing solution was added before the absorbance was measured at $450 \mathrm{~nm}$ using an ELISA reader (Multiskan EX, Thermo Scientific, Vantaa, Finland).

2.8. Cell Morphology Observed by Immunofluorescence Staining. The SH-SY5Y cells were grown on coverslips in 12-well culture plates. After 24 hours' incubation, the cells were fixed (60\% methanol and $40 \%$ acetone) at $-20^{\circ} \mathrm{C}$ for $30 \mathrm{~min}$ and then permeabilized ( $0.5 \%$ Triton X-100) at room temperature for $5 \mathrm{~min}$. After rinsing with PBS, the cells were blocked (6\% bovine serum albumin) and then incubated with primary and secondary antibodies. The nuclei and cytoskeleton of the cells were stained with DAPI (Sigma-Aldrich, USA), vimentin (Vimentin DyLight 488 Antibody, Epitomics, USA), monoclonal mouse anti-HSP60 (Stressgen, USA), and polyclonal rabbit anti-RanBP2 (Abcam, USA), respectively. After rinsing with PBS, the cells were mounted with ProLong ${ }^{\circledR}$ Gold Antifade Reagent (Invitrogen). The images were acquired by a microscope equipped with fluorescence light source (FLoid Cell Fluorescence Imaging Station, Invitrogen).

2.9. Statistical Analysis. All calculations used the SigmaStat statistical software (Jandel Science Corp., San Rafael, CA, USA). All statistical significance was evaluated at $95 \%$ of confidence level or better. Data are presented as mean \pm standard error.

\section{Results and Discussion}

3.1. Quantitative Analysis of Adsorbed of $H A$ and Adhesion of SH-SY5Y Cells on Electrodes Using QCM Techniques. In our previous studies, the QCM system was applicable to the quantitative analysis of adsorption of HA and adhesion of cells on electrodes $[42,43]$. The QCM frequency variation after HA-biopolymer formation was $-212.47 \pm 6.33 \mathrm{~Hz}$; the adsorbed HA mass corresponding to those surfaces was $228.11 \pm 3.30 \mathrm{ng}$. To investigate the adhesion of SH-SY5Y cells onto electrodes decorated by HA surface with PC12 CM, SHSY5Y cells were incubated on the electrodes. The cultivation of SH-SY5Y cells under serum-free conditions after 12 hours herein prevented the apoptosis and proliferation of cells, which were then changed to DMEM/F12 medium without or with $\mathrm{PC} 12 \mathrm{CM}$. The results concerning the adhesion of $\mathrm{SH}-$ SY5Y cells onto the electrode of QCM that was decorated by HA were obtained from the frequency shifts. The frequency shifts for HA-modified surfaces without or with PC12 CM were from $-3.68 \pm 0.42$ to $-10.47 \pm 0.27 \times 10^{3} \mathrm{~Hz}$; the attached cell mass corresponding to HA surface was from $1.13 \pm 0.13$ to $3.22 \pm 0.08 \times 10^{3} \mathrm{ng}$, respectively (Table $1, n=10$ ). With treatment of PC12 CM after 48 and 72 hours, the frequency shift was lowered and the mass of cell was increased from that of regular medium. These results indicated that PC12 CM may be beneficial to SH-SY5Y cells adhesion or proliferation.

3.2. Investigation of HA Structure by FT-IR. HA-modified surfaces of coverslips were also routinely characterized using
TABLE 1: Frequency shifts of QCM and weights of adhered SH-SY5Y cells on the electrodes decorated with HA-modified surface for 24 to 72 hours of cell incubation.

\begin{tabular}{lcc}
\hline Cell adhesion & $\Delta F\left(\times 10^{3} \mathrm{~Hz}\right)$ & $\Delta m\left(\times 10^{3} \mathrm{ng}\right)$ \\
\hline DMEM/F12 medium & & \\
$24 \mathrm{hrs}$ & $-3.68 \pm 0.42$ & $1.13 \pm 0.13$ \\
$48 \mathrm{hrs}$ & $-4.70 \pm 0.48$ & $1.44 \pm 0.15$ \\
$72 \mathrm{hrs}$ & $-4.93 \pm 0.69$ & $1.51 \pm 0.21$ \\
DMEM/F12 medium-PC12 CM & & \\
$24 \mathrm{hrs}$ & $-6.30 \pm 1.35$ & $1.94 \pm 0.42^{*}$ \\
$48 \mathrm{hrs}$ & $-10.83 \pm 0.58$ & $3.33 \pm 0.18^{*}$ \\
$72 \mathrm{hrs}$ & $-10.47 \pm 0.27$ & $3.22 \pm 0.08^{*}$ \\
\hline
\end{tabular}

Data are expressed as mean \pm standard error, $n=10,{ }^{*} p<0.05$ (t-test).

TABLE 2: The assignment of FT-IR bands for HA-modified surface.

\begin{tabular}{lc}
\hline Function group & Wavenumber $\left(\mathrm{cm}^{-1}\right)$ \\
\hline $\begin{array}{l}\mathrm{C}-\mathrm{O}-\mathrm{C} \text { stretching, O-H deformation, } \\
\mathrm{C}=\mathrm{O} \text { deformation }\end{array}$ & 894.9 \\
$\mathrm{C}-\mathrm{O}-\mathrm{C}, \mathrm{C}-\mathrm{O}, \mathrm{C}-\mathrm{O}-\mathrm{H}$ stretching & 1049.1 \\
$\mathrm{CH}_{2}, \mathrm{CH}_{3} \mathrm{C}-\mathrm{O}-\mathrm{H}$ deformation, C-O with & 1321.0 \\
$\mathrm{C}=\mathrm{O}$ combination & 1406.9 \\
$\mathrm{NH}$ deformation & 1616.1 \\
$\mathrm{C}=\mathrm{O}$ carboxyl amide I & 2893.8 \\
$\mathrm{CH}$ stretching & 3261.2 \\
$\mathrm{NH}$ with C=O combination & 3433.8 \\
$\mathrm{NH}$ stretching and OH stretching &
\end{tabular}

FT-IR spectra. The FR-IR spectra in the range of 500$4000 \mathrm{~cm}^{-1}$ for HA surfaces were presented in Figure 1. Expansion of the FT-IR spectra in Figure 1 clearly showed the difference between spectra of nonmodified and HAmodified coverslips. The HA-modified surface showed several sharp peaks such as at 894.9 and $1049.1 \mathrm{~cm}^{-1}$ that could be due to the $\mathrm{C}-\mathrm{O}-\mathrm{C}$ stretching, at $1321.0 \mathrm{~cm}^{-1}$ that corresponds to the presence of $\mathrm{C}-\mathrm{O}$ with $\mathrm{C}=\mathrm{O}$ combination, at $1406.9 \mathrm{~cm}^{-1}$ that indicates the presence of $\mathrm{NH}$ deformation, at $1616.1 \mathrm{~cm}^{-1}$ due to the $\mathrm{C}=\mathrm{O}$ carboxyl amide $\mathrm{I}$, and at 2893.8 to $3433.8 \mathrm{~cm}^{-1}$ that confirms the presence of $\mathrm{CH}$ stretching, and $\mathrm{NH}$ with $\mathrm{C}=\mathrm{O}$ combination and $\mathrm{OH}$ stretching. Similar peaks were indicated in Table 2 . These peaks obtained in the HA-modified surface share a highly similar position when compared to the standard HA.

3.3. Combination Treatment of HA and PC12 CM Increased SH-SY5Y Cell Proliferation. HA is well known to promote fibroblasts proliferation and enhance cell adhesion [42]. To investigate the HA and PC12 CM effect on SH-SY5Y cells, the cell proliferation was assessed. The $4 \times 10^{4} \mathrm{SH}-\mathrm{SY} 5 \mathrm{Y}$ cells were seeded and grown on HA-modified and nonmodified coverslips. The cell proliferation was measured by BrdU assay for 24,48 , or 72 hours and the baseline of cell proliferation was set at 12 hours after seeding. As shown in Figure 2, $\mathrm{SH}-\mathrm{SY} 5 \mathrm{Y}$ cell proliferation rates on HA-modified coverslips 


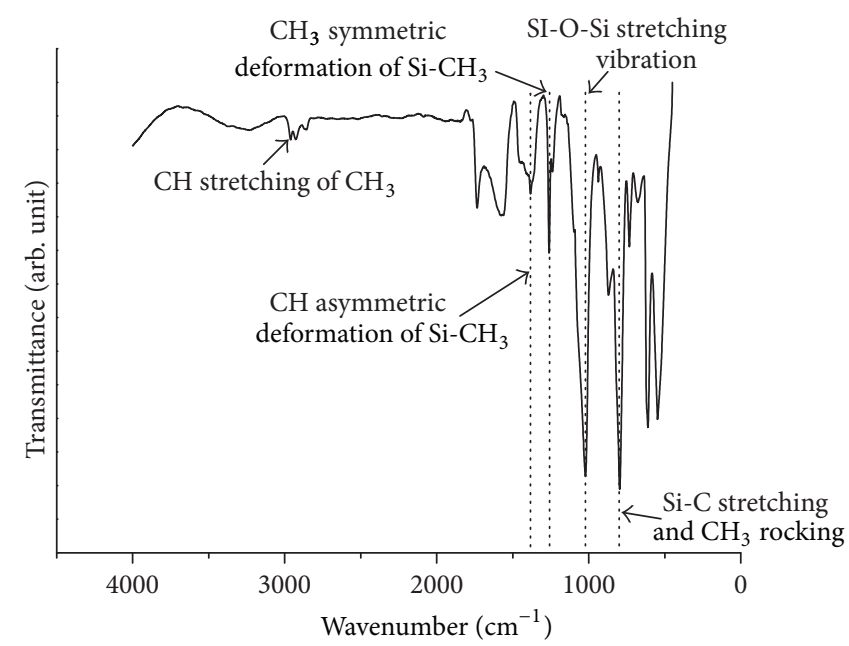

(a)

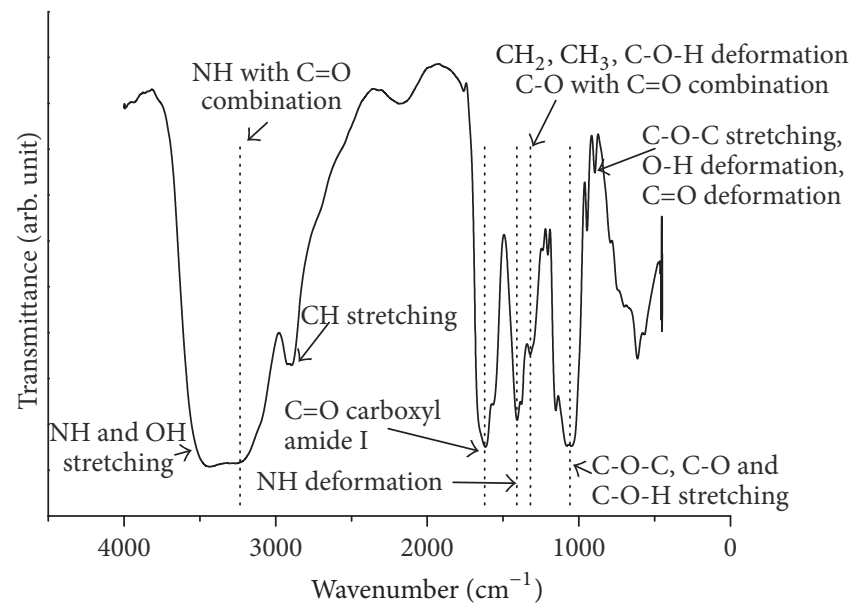

(b)

FIGURE 1: The FT-IR spectra show the frequency region from 4000 to $500 \mathrm{~cm}^{-1}$ of modified surfaces and (a) nonmodified and (b) HA-modified coverslips.

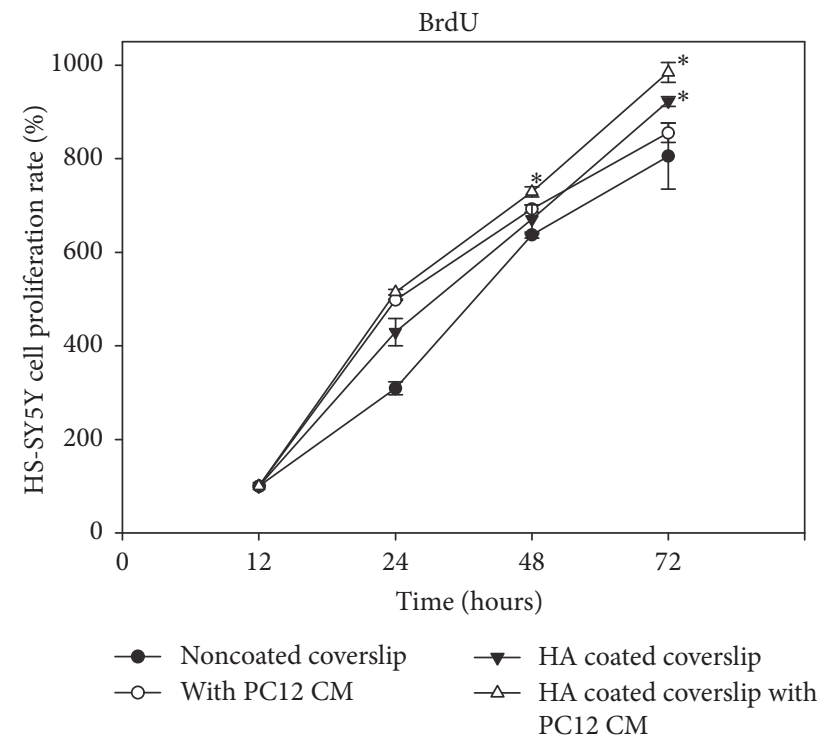

Figure 2: The relative percentage of cell viability obtained from BrdU cell proliferation assay. Differential treatments of SH-SY5Y cells were seeded in 96-well tissue culture plates and incubated for 24 to $72 \mathrm{~h}$. Cells were treated with BrdU reagent for $2 \mathrm{~h}$ and fixed before the absorbance was measured at $450 \mathrm{~nm}$.

were similar to those of nonmodified coverslips of 48 hours. However, the SH-SY5Y cell proliferation rate was increased significantly after 72 hours on the HA-modified coverslips.

The PC12 CM was collected and added to the culture medium of the SH-SY5Y cell. After 48 hours' incubation, the results showed that PC12 CM induced SH-SY5Y cell growth and proliferation especially with the HA-modified surface. The HA-modified coverslip combined with treatment of PC12 CM promoted SH-SY5Y cell proliferation after 72 hours' incubation as indicated in Figure 2 using BrdU assay. Therefore, HA and PC12 CM were the two factors with a synergistic effect.
To understand the mechanism and consequence of the increasing of the SH-SY5Y cell proliferation and growth, the proteins in PC12 CM and SH-SY5Y cell lysate were identified by proteomic approaches.

3.4. Identification of Regulator Secreted from PC12. To identify the PC12 secreted proteins related to SH-SY5Y cell proliferation and cell adhesion, the original PC12 CM were collected and the proteins were identified by RP-nano-HPLCESI-MS/MS. One hundred seventy-three HA-modified surface proteins were identified and then narrowed down to the number 62, using a threshold of a minimum of three peptides identified in a protein. We found that several proteins (described below) are involved in cell differentiation functions. Table 3 shows the details of the protein identification (protein accession number, protein name, biological process, and molecular function) in PC12 CM.

The expression of Gametogenetin (GGN) was confined to late pachytene spermatocytes and round spermatids, a time window concomitant with the occurrence of meiosis. It was expressed with highest level in diplotene spermatocytes and meiotic germ cells, especially when the nuclear membrane breaks down and the nucleolus is disorganized. In addition to functioning in proliferation of primordial germ cells, POG also involved in spermatogenesis [44].

Adrenomedullin (ADM) is a member of the calcitonin gene-related peptide (CGRP) family, which has shown neuroprotective functions [45]. ADM is secreted in many organs and tissues [46], and so were PC12 cells. ADM mediates downstream signaling through calcitonin receptorlike receptor (CRL)-receptor-activity-modifying proteins (RAMPs) complex [46].

Spermatid perinuclear RNA-binding protein (SPNR) is a microtubule-associated RNA-binding protein [47]. SPNR gene has been detected in the testis, ovary, and brain [48]. Mice deficient for SPNR show neurologic, spermatogenic, and sperm morphological abnormalities [49]. In our study, 
TABLE 3: Proteins identified by the higher confidence level (at least three unique peptide sequences matched) in the PC12 CM which were involved in neuron generation function.

\begin{tabular}{|c|c|c|c|}
\hline $\begin{array}{l}\text { Accession } \\
\text { numbers }\end{array}$ & Protein name & Biological process & Molecular function \\
\hline \multirow[t]{4}{*}{ Q66HC8 } & Gametogenetin & Cell differentiation & \\
\hline & & Double-strand break repair & \\
\hline & & Embryo implantation & \\
\hline & & Spermatogenesis & \\
\hline \multirow[t]{8}{*}{ P43145 } & $\mathrm{ADM}$ & Aging & Adrenomedullin receptor binding \\
\hline & & Androgen metabolic process & \\
\hline & & Calcium ion homeostasis & \\
\hline & & cAMP-mediated signaling & \\
\hline & & Hormone secretion & \\
\hline & & Vasculogenesis & \\
\hline & & Cell proliferation & \\
\hline & & Apoptotic process & \\
\hline \multirow[t]{3}{*}{ Q9JKU6 } & $\begin{array}{l}\text { Spermatid perinuclear } \\
\text { RNA-binding protein }\end{array}$ & Cell differentiation & DNA binding \\
\hline & & Multicellular organismal development & RNA binding \\
\hline & & Spermatogenesis & \\
\hline \multirow[t]{3}{*}{ O35569 } & $\begin{array}{l}\text { Pro-neuregulin-2, } \\
\text { membrane-bound isoform }\end{array}$ & Epidermal growth factor receptor signaling pathway & $\begin{array}{l}\text { Epidermal growth factor receptor } \\
\text { binding }\end{array}$ \\
\hline & & Intracellular signal transduction & ErbB-3 class receptor binding \\
\hline & & Organ development & \\
\hline \multirow[t]{8}{*}{ Q62956 } & $\begin{array}{l}\text { Receptor tyrosine-protein } \\
\text { kinase erbB- } 4\end{array}$ & Cardiac muscle tissue regeneration & ATP binding \\
\hline & & Cell migration & $\begin{array}{l}\text { Receptor signaling protein tyrosine } \\
\text { kinase activity }\end{array}$ \\
\hline & & Nervous system development & $\begin{array}{l}\text { Transmembrane receptor protein } \\
\text { tyrosine kinase activity }\end{array}$ \\
\hline & & Apoptotic process & \\
\hline & & Cell proliferation & \\
\hline & & Glucose import & \\
\hline & & Odontogenesis & \\
\hline & & Protein tyrosine kinase Signaling pathway & \\
\hline \multirow[t]{7}{*}{ P01026 } & Complement C3 & Blood coagulation & $\begin{array}{l}\text { C5L2 anaphylatoxin chemotactic } \\
\text { receptor binding }\end{array}$ \\
\hline & & Chemotaxis & Cofactor binding \\
\hline & & Fatty acid metabolic process & Endopeptidase inhibitor activity \\
\hline & & Inflammatory response & Lipid binding \\
\hline & & Glucose transport & \\
\hline & & Triglyceride biosynthetic process & \\
\hline & & Response to progesterone and estrogen & \\
\hline \multirow[t]{5}{*}{ Q9R172 } & $\begin{array}{l}\text { Neurogenic locus notch } \\
\text { homolog protein } 3\end{array}$ & Cell differentiation & Calcium ion binding \\
\hline & & Multicellular organismal development & \\
\hline & & Notch signaling pathway & \\
\hline & & Regulation of transcription, DNA-templated & \\
\hline & & Tissue regeneration & \\
\hline
\end{tabular}




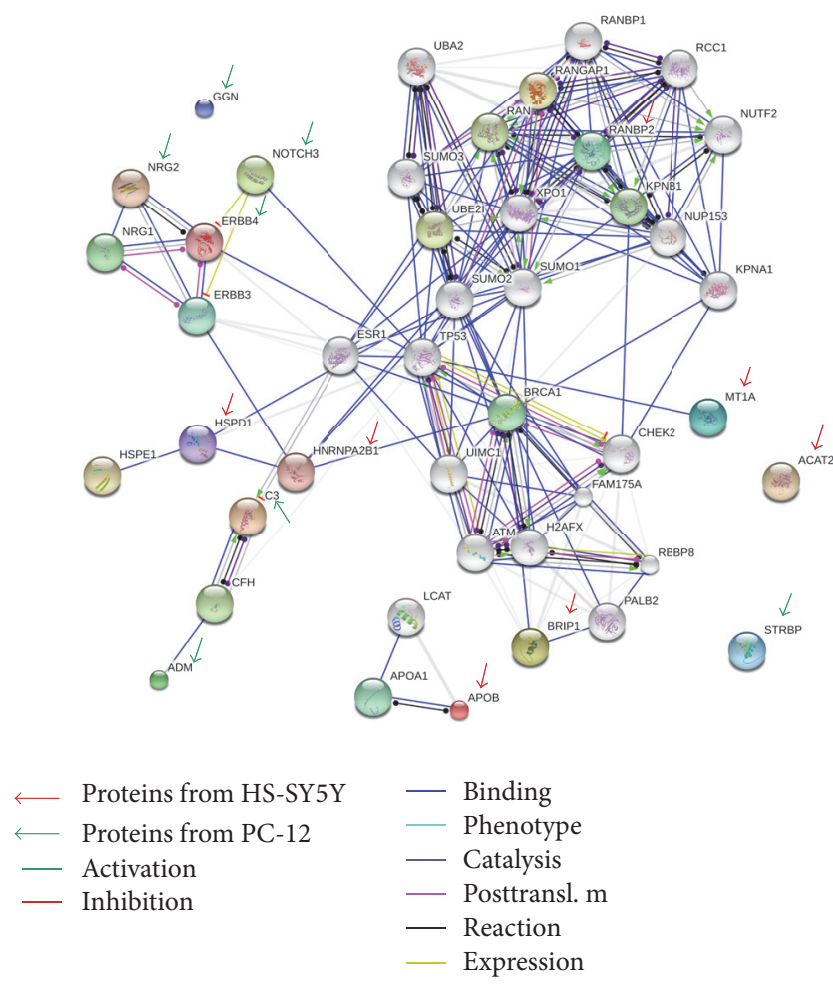

(a)

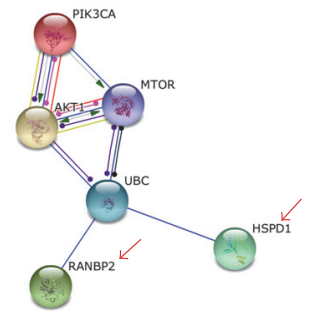

(b)

FIGURE 3: The protein-protein interaction pathways are illustrated. (a) Proteins identified in this study are marked by arrows (red: SH-SY5Y; green: PC12). (b) Two proteins, HSP60 and RanBP2, may turn on the ubiquitin (UBC) pathway, which is responsible for the proliferation and is required for survival of the majority of cells.

SPNR was detected in PC12 CM. This finding indicates that SPNR may be involved in neuron cell development.

The Pro-neuregulin-2 (Nrg2) has played a critical role in the growth and development of multiple organ systems, which was also involved in neural and organ development. In the embryo, the Nrg2 was expressed in the brain where it was found in the telencephalon, but not in the hindbrain. The Nrg2 was direct ligand for ErbB 3 and ErbB 4 tyrosine kinase receptors. Concomitantly recruiting ErbB 1 and ErbB 2 coreceptors, the Nrg2 may result in ligand-stimulated tyrosine phosphorylation and activation of the ErbB receptors, which may also promote the heterodimerization with the EGF receptor [50].

NRG1/ErbB signaling pathways are important in CNS development and may be neuroprotective in brain injury [51]. ErbB4 is predominantly expressed in the brain and well characterized for its function in the CNS [52]. In the CNS, NRG1/ErbB4 signaling is involved in neuronal migration, dendritic spine maturation, and the formation of inhibitory synapses onto excitatory pyramidal neurons [51]. ErbB4 mutant mice were showed to alter the organization and migration of neuroblast chain and display olfactory interneurons deficits in the placement and differentiation [53].

The complement system plays an important role in inflammatory diseases and neurodegenerative processes of the CNS [54]. C3a, one of complement factors, has been shown to be involved in synaptic refinement regulation and neuronal survival during development in the CNS [55].

The interaction of Notch, with its established intercellular signaling pathway, plays a key role in neural development. The Notch-3 activation induces the increase of the progenitor cell number in the central nervous system (CNS) and affects CNS development [56]. The Notch-3 mutation may lead to cerebral autosomal dominant arteriopathy with subcortical infarcts and leukoencephalopathy (CADASIL). CADASIL leads to stroke and dementia and is the main feature of recurrent subcortical ischemic events and vascular dementia. Members of the Notch gene family were thought to be involved as receptors for membrane-bound ligands Jagged1, Jagged2, and Delta1 in the regulation of cell fate in a variety of neurogeneses of embryos, particularly in the developing CNS from the homogenous cell population of the neural tube $[57,58]$.

Also, in this study, more than one hundred proteins were identified in SH-SY5Y cell lysate and most of these were identified at the minimal confidence level, which was only one unique peptide sequence matched. Experimental results reported a total of six protein identifications with higher confidence levels (at least three unique peptide sequences matched). The protein-protein interaction pathways were performed by String 9.1 Web software, and proteins identified in this study were marked by arrows (red: SH-SY5Y; green: PC12; Figure 3(a)). Using the protein-protein interaction 

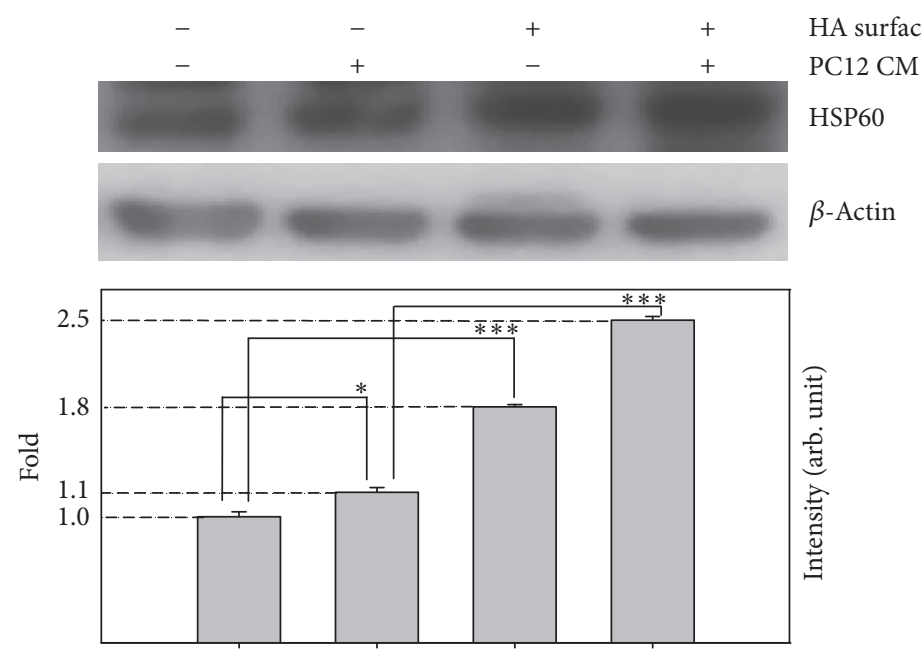

(a)

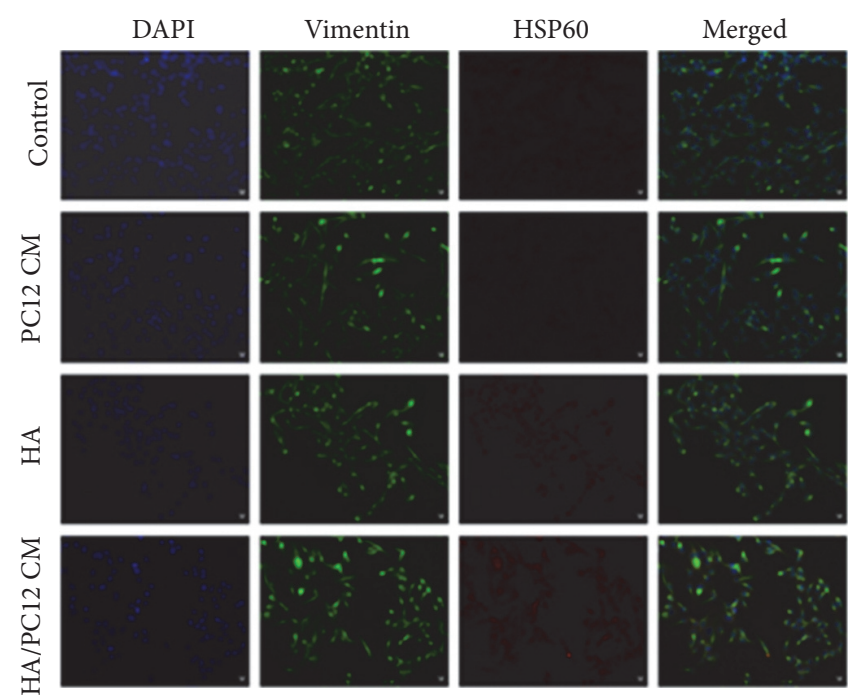

(b)

Figure 4: The detection of HSP60 protein expression on SH-SY5Y cells. (a) Western blotting of HSP60 and $\beta$-actin from SH-SY5Y cells cultured on different surfaces and/or different medium. The signals were quantified and the data are presented as the means \pm SEMs; $p<0.05$ or 0.001 indicates statistical significance, as determined by unpaired Student's $t$-test. (b) Analyses of representative samples of SH-SY5Y cells expression of vimentin and HSP60 are shown. Immunochemical stains for DAPI (blue), vimentin (green), and HSP60 (red) for adhered SH-SY5Y cells on indicated surfaces and/or conditioned media for $24 \mathrm{~h}$ (scale bars, $10 \mu \mathrm{m}$; confocal microscope, $400 \mathrm{x}$ ). ${ }^{*} p<0.05$ and ${ }^{* * *} p<0.001$.

pathway analysis, the main finding of PC12 CM-treated cells is that the growth factors may focus on the enhancement of the TP53 pathway in SH-SY5Y cells which may result in cell growth (Figure 3(b)).

The TP53 pathway has been famously recognized to be connected to the UBC/PI3K/AKT1/mTOR pathway, which is responsible for the proliferation and is required for survival of the majority of cells. The hypothesis of the mTOR pathway is that it acts as a master switch of cellular catabolism and anabolism, thereby determining whether cells grow and proliferate. In particular, the UBC/PI3K/AKT1/mTOR pathway regulates the import and retention of glucose. It provides substrates for glycolysis and the biosynthetic pathways which rely on the supply of glycolytic intermediates. The mTOR pathway, downstream of AKT signaling, regulates the protein translation rate and accelerates the supply of amino acid biosynthesis to generate the charged tRNAs [59].

To confirm this hypothesis, the proteins in SH-SY5Y cell lysate need to be validated. In addition, there were two proteins, $60 \mathrm{kDa}$ heat shock protein (HSP60, known as HSPD1) and E3 SUMO-protein ligase RanBP2 (RanBP2), identified in SH-SY5Y cell lysate samples, which were involved in cell proliferation, differentiation, development, and cycle regulation. Those two proteins were also involved in the UBC/ 


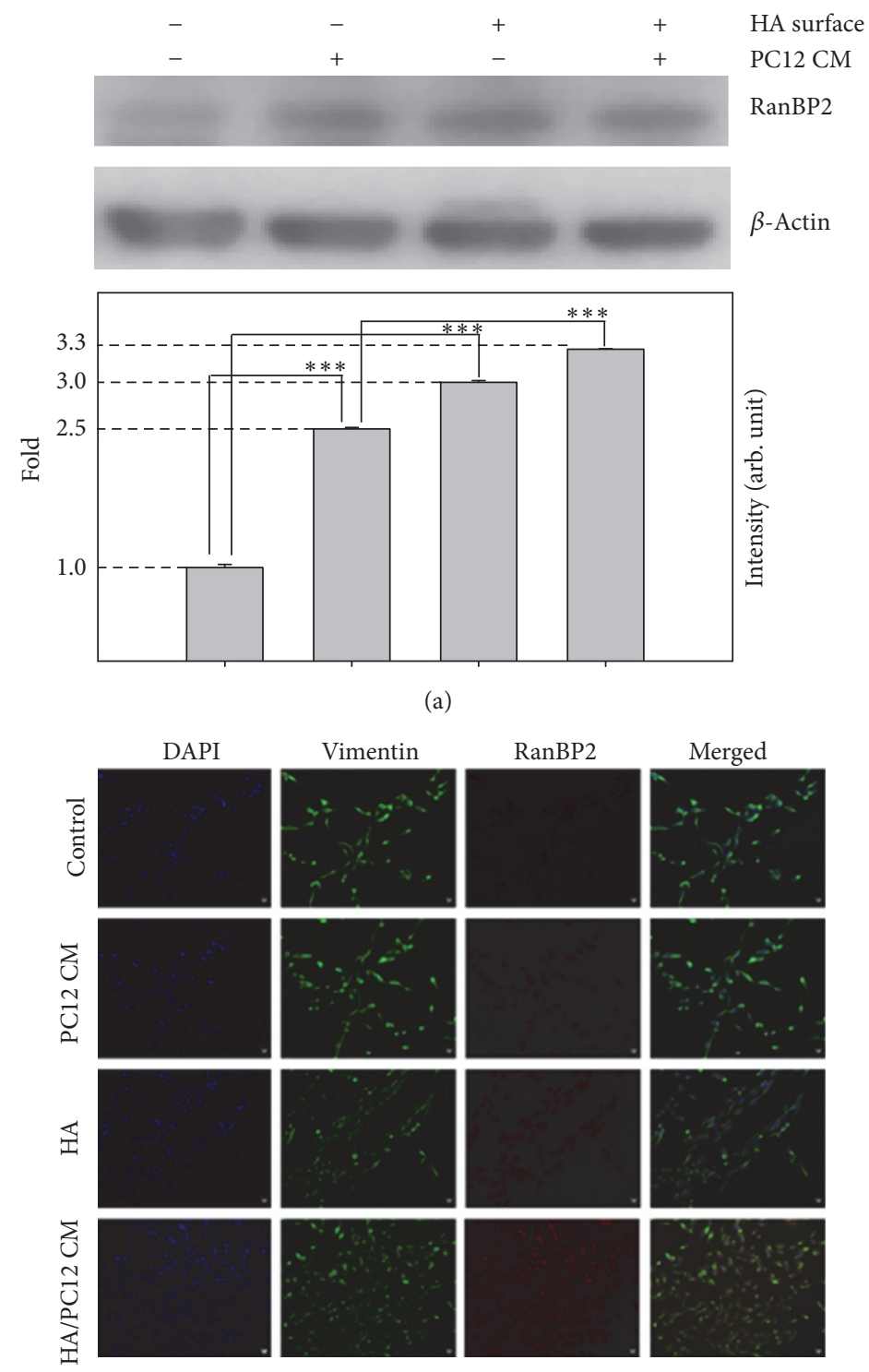

(b)

FIGURE 5: The detection of RanBP2 protein expression on SH-SY5Y cells. (a) Western blotting of RanBP2 and $\beta$-actin from SH-SY5Y cells cultured on different surfaces and/or different medium. The signals were quantified and the data are presented as the means \pm SEMs; $p<0.001$ indicates statistical significance, as determined by unpaired Student's $t$-test. (b) Analyses of representative samples of SH-SY5Y cells expression of vimentin and RanBP2 are shown. Immunochemical stains for DAPI (blue), vimentin (green), and RanBP2 (red) for adhered SH-SY5Y cells on indicated surfaces and/or conditioned media for $24 \mathrm{~h}$ (scale bars, $10 \mu \mathrm{m}$; confocal microscope, $400 \mathrm{x}) .{ }^{* * *} p<0.001$.

PI3K/AKT1/mTOR pathway (Figure 3(b)). To corroborate the protein candidates identified by RP-nano-HPLC-ESIMS/MS, the Western blot analysis and immunofluorescence staining were applied to detect the changes in HSP60 and RanBP2.

Heat shock proteins (HSPs) are overexpressed in a wide range of cells and are implicated in cell proliferation, differentiation, and recognition by the immune system. These proteins have molecular chaperone activity, which can be induced by various environmental stresses. Some HSPs were found to be localized in the synapse [60]. HSP60 is widely distributed in the brain and involved in neurodegenerative disorders [61]. When injured, HSP60 can be released to activate microglia in CNS [62]. HSP60 defects can cause neurodegenerative pathologies, such as brain hypomyelination and leukodystrophy [63]. Here, we found the protein expressions of HSP60 were upregulated in HA-modified surface or PC12 CM-treated SH-SY5Y cells compared to control, and the effect was significantly enhanced by the above-mentioned combination (Figure 4(a)). Immunofluorescence staining also showed that cotreatment with HAmodified surface and PC12 CM increased HSP60 expression 
in SH-SY5Y cells (Figure 4(b)). These results suggested that $\mathrm{HA}$ and PC12 CM may trigger HSP60 as part of its nerve regeneration effects.

RanBP2, located at the nuclear pore complexes (NPCs) [64], is known to modulate CRM1-mediated nuclear protein export [65] and associate with Ubc9 to function as a SUMO E3 ligase [66-68]. RanBP2 also plays a role in neuroprotective regulation [69-71]. RanBP2 associates with RPGRIP1 to implicate retinopathies in amacrine and 661W neurons [72]. RanBP2 mutation has been identified as a key factor in acute necrotising encephalopathy $[73,74]$. Here, the protein expression levels of RanBP2 in PC12 CM-treated or HAmodified surface treated SH-SY5Y cells were higher than those from control cells. Cotreatment with HA-modified surface and PC12 CM slightly increased RanBP2 protein expression compared with HA-modified surface or PC12 CM (Figure 5(a)). Immunofluorescence staining also showed the similar results that the expression of RanBP2 was increased in PC12 CM-treated and HA-modified surface with PC12 CMtreated SH-SY5Y cells (Figure 5(b)). Thus, HA and PC12 CM may upregulate RanBP2 protein expression as part of its nerve neuroprotective effects.

In the result, it showed that $\mathrm{HA}$ and $\mathrm{PC} 12 \mathrm{CM}$ may regulate protein expression, such as HSP60 and RanBP2 to promote SH-SY5Y cell proliferation and adhesion. These results were similar to Yamada's study, which reported that the combination treatment of SHya and FGF-2 increased NHA proliferation [75]. HA biomaterial surface has been used and reported in a wide range of medical and biological applications and plays an important role in neural development $[25,28]$. Due to the activation of UBC/PI3K/AKT1/mTOR, signaling through mutation of pathway components as well as through activation of upstream signaling molecules occurs in a majority of cells contributing to deregulation of proliferation, resistance to apoptosis, and changes in metabolism characteristic of transforming cells.

\section{Conclusion}

In this study, SH-SYSY cells were used as a model to examine the effects of HA and PC12 CM in neuron regeneration. We found that stimulation of a HA-modified surface with PC12 CM can promote SH-SYSY cell proliferation and adhesion; the combination of both showed synergy effects on SH-SYSY cell regeneration. Our evidences supported that neurotrophic factor proteins enhance HA function in neurogenesis. Biomaterial surface supported with neurotrophic factor proteins may be utilized in nerve autograft application. We used proteomic analysis to analyze the molecular mechanisms of HA-modified surface and PC12 CM stimuli. Among these proteins, HSP60 and RanBP2 were upregulated in SH-SY5Y cells. The UBC/PI3K/AKT1/mTOR pathway was related to the cell growth and proliferation. Future study will be of the molecular regulations and interaction networks governed by biomaterials and combined with neurotrophic factors.

\section{Competing Interests}

The authors declare no conflict of interests.

\section{Authors' Contributions}

Ming-Hui Yang and Ko-Chin Chen contributed equally to this work.

\section{Acknowledgments}

The authors thank S. Sheldon (Medical Technologist, American Society of Clinical Pathology, retired, MT, ASCP) of Oklahoma University Medical Center Edmond for fruitful discussions and editorial assistance. The authors thank the Center of Excellence for Environmental Medicine, Kaohsiung Medical University, for the assistance in protein identification. This work was supported by Research Grants MOST 103-2320-B-037-025 and MOST 105-0210-01-12-01 (Taiwan Protein Project) from the Ministry of Science and Technology, KMU-TP104E12 and KMU-O104003 (Aim for the Top 500 Universities Grant) from Kaohsiung Medical University, 105-CCH-KMU-005 from CCH-KMU Research Project, and NSYSUKMU104-P032 from NSYSU-KMU Research Project, Taiwan.

\section{References}

[1] W. Daly, L. Yao, D. Zeugolis, A. Windebank, and A. Pandit, "A biomaterials approach to peripheral nerve regeneration: bridging the peripheral nerve gap and enhancing functional recovery," Journal of the Royal Society Interface, vol. 9, no. 67, pp. 202-221, 2012.

[2] A. Muheremu and Q. Ao, "Past, present, and future of nerve conduits in the treatment of peripheral nerve injury," BioMed Research International, vol. 2015, Article ID 237507, 6 pages, 2015.

[3] X. Jiang, S. H. Lim, H.-Q. Mao Hai-Quan, and S. Y. Chew, "Current applications and future perspectives of artificial nerve conduits," Experimental Neurology, vol. 223, no. 1, pp. 86-101, 2010.

[4] S. Rochkind and Z. Nevo, "Recovery of peripheral nerve with massive loss defect by tissue engineered guiding regenerative gel," BioMed Research International, vol. 2014, Article ID 327578, 7 pages, 2014.

[5] X. Navarro, M. Vivó, and A. Valero-Cabré, "Neural plasticity after peripheral nerve injury and regeneration," Progress in Neurobiology, vol. 82, no. 4, pp. 163-201, 2007.

[6] T. Sedaghati and A. M. Seifalian, "Nanotechnology and biofunctionalisation for peripheral nerve regeneration," Neural Regeneration Research, vol. 10, no. 8, pp. 1191-1194, 2015.

[7] E. O. Johnson and P. N. Soucacos, "Nerve repair: experimental and clinical evaluation of biodegradable artificial nerve guides," Injury, vol. 39, S3, pp. S30-S36, 2008.

[8] D. J. Bryan, A. H. Holway, K.-K. Wang et al., "Influence of glial growth factor and Schwann cells in a bioresorbable guidance channel on peripheral nerve regeneration," Tissue Engineering, vol. 6, no. 2, pp. 129-138, 2000.

[9] G. R. D. Evans, K. Brandt, A. D. Niederbichler et al., "Clinical long-term in vivo evaluation of poly(L-lactic acid) porous conduits for peripheral nerve regeneration," Journal of Biomaterials Science, Polymer Edition, vol. 11, no. 8, pp. 869-878, 2000.

[10] M. Richards, B. I. Dahiyat, D. M. Arm, P. R. Brown, and K. W. Leong, "Evaluation of polyphosphates and polyphosphonates 
as degradable biomaterials," Journal of Biomedical Materials Research, vol. 25, no. 9, pp. 1151-1167, 1991.

[11] H. J. Hoppen, J. W. Leenslag, A. J. Pennings, B. van der Lei, and P. H. Robinson, "Two-ply biodegradable nerve guide: basic aspects of design, construction and biological performance," Biomaterials, vol. 11, no. 4, pp. 286-290, 1990.

[12] R. F. Valentini, T. G. Vargo, J. A. Gardella Jr., and P. Aebischer, "Electrically charged polymeric substrates enhance nerve fibre outgrowth In vitro," Biomaterials, vol. 13, no. 3, pp. 183-190, 1992.

[13] P. D. Dalton, L. Flynn, and M. S. Shoichet, "Manufacture of poly(2-hydroxyethyl methacrylate-co-methyl methacrylate) hydrogel tubes for use as nerve guidance channels," Biomaterials, vol. 23, no. 18, pp. 3843-3851, 2002.

[14] S. J. Archibald, C. Krarup, J. Shefner, S.-T. Li, and R. D. Madison, "A collagen-based nerve guide conduit for peripheral nerve repair: an electrophysiological study of nerve regeneration in rodents and nonhuman primates," Journal of Comparative Neurology, vol. 306, no. 4, pp. 685-696, 1991.

[15] T. Jiang, S. G. Kumbar, L. S. Nair, and C. T. Laurencin, "Biologically active chitosan systems for tissue engineering and regenerative medicine," Current Topics in Medicinal Chemistry, vol. 8, no. 4, pp. 354-364, 2008.

[16] C. E. Dumont and V. R. Hentz, "Enhancement of axon growth by detergent-extracted nerve grafts," Transplantation, vol. 63, no. 9, pp. 1210-1215, 1997.

[17] B. P. Toole, "Hyaluronan in morphogenesis," Seminars in Cell and Developmental Biology, vol. 12, no. 2, pp. 79-87, 2001.

[18] P. Rooney, S. Kumar, J. Ponting, and M. Wang, "The role of hyaluronan in tumour neovascularization (review)," International Journal of Cancer, vol. 60, no. 5, pp. 632-636, 1995.

[19] M. Slevin, J. Krupinski, S. Kumar, and J. Gaffney, "Angiogenic oligosaccharides of hyaluronan induce protein tyrosine kinase activity in endothelial cells and activate a cytoplasmic signal transduction pathway resulting in proliferation," Laboratory Investigation, vol. 78, no. 8, pp. 987-1003, 1998.

[20] M. Slevin, S. Kumar, and J. Gaffney, "Angiogenic oligosaccharides of hyaluronan induce multiple signaling pathways affecting vascular endothelial cell mitogenic and wound healing responses," Journal of Biological Chemistry, vol. 277, no. 43, pp. 41046-41059, 2002.

[21] M. Preston and L. S. Sherman, "Neural stem cell niches: roles for the hyaluronan-based extracellular matrix," Frontiers in Bioscience-Scholar, vol. 3, no. 3, pp. 1165-1179, 2011.

[22] R. U. Margolis, R. K. Margolis, L. B. Chang, and C. Preti, "Glycosaminoglycans of brain during development," Biochemistry, vol. 14, no. 1, pp. 85-88, 1975.

[23] D. Jiang, J. Liang, and P. W. Noble, "Hyaluronan in tissue injury and repair," Annual Review of Cell and Developmental Biology, vol. 23, pp. 435-461, 2007.

[24] J. Liang, D. Jiang, and P. W. Noble, "Hyaluronan as a therapeutic target in human diseases," Advanced Drug Delivery Reviews, vol. 97, pp. 186-203, 2016.

[25] L. S. Sherman, S. Matsumoto, W. Su, T. Srivastava, and S. A. Back, "Hyaluronan synthesis, catabolism, and signaling in neurodegenerative diseases," International Journal of Cell Biology, vol. 2015, Article ID 368584, 10 pages, 2015.

[26] M. A. Solis, Y.-H. Chen, T. Y. Wong, V. Z. Bittencourt, Y.-C. Lin, and L. L. H. Huang, "Hyaluronan regulates cell behavior: a potential niche matrix for stem cells," Biochemistry Research International, vol. 2012, Article ID 346972, 11 pages, 2012.
[27] J. Arulmoli, H. J. Wright, D. T. Phan et al., "Combination scaffolds of salmon fibrin, hyaluronic acid, and laminin for human neural stem cell and vascular tissue engineering," Acta Biomaterialia, vol. 43, pp. 122-138, 2016.

[28] J. J. Greene and D. M. Sidle, “The hyaluronic acid fillers. Current understanding of the tissue device interface," Facial Plastic Surgery Clinics of North America, vol. 23, no. 4, pp. 423-432, 2015.

[29] P. Moshayedi and S. T. Carmichael, "Hyaluronan, neural stem cells and tissue reconstruction after acute ischemic stroke," Biomatter, vol. 3, no. 1, Article ID e23863, 2013.

[30] Z. Z. Khaing, B. D. Milman, J. E. Vanscoy, S. K. Seidlits, R. J. Grill, and C. E. Schmidt, "High molecular weight hyaluronic acid limits astrocyte activation and scar formation after spinal cord injury," Journal of Neural Engineering, vol. 8, no. 4, Article ID 046033, 2011.

[31] Z.Z. Khaing and S. K. Seidlits, "Hyaluronic acid and neural stem cells: implications for biomaterial design," Journal of Materials Chemistry B, vol. 3, no. 40, pp. 7850-7866, 2015.

[32] G. Lisignoli, S. Cristino, A. Piacentini et al., "Cellular and molecular events during chondrogenesis of human mesenchymal stromal cells grown in a three-dimensional hyaluronan based scaffold," Biomaterials, vol. 26, no. 28, pp. 5677-5686, 2005.

[33] N. P. Rhodes, J. K. Srivastava, R. F. Smith, and C. Longinotti, "Metabolic and histological analysis of mesenchymal stem cells grown in 3-D hyaluronan-based scaffolds," Journal of Materials Science: Materials in Medicine, vol. 15, no. 4, pp. 391-395, 2004.

[34] P. C. Baer, J. Bereiter-Hahn, C. Missler et al., "Conditioned medium from renal tubular epithelial cells initiates differentiation of human mesenchymal stem cells," Cell Proliferation, vol. 42, no. 1, pp. 29-37, 2009.

[35] Y.-S. Hwang, W. L. Randle, R. C. Bielby, J. M. Polak, and A. Mantalaris, "Enhanced derivation of osteogenic cells from murine embryonic stem cells after treatment with HepG2conditioned medium and modulation of the embryoid body formation period: application to skeletal tissue engineering," Tissue Engineering, vol. 12, no. 6, pp. 1381-1392, 2006.

[36] T.-J. Lee, J. Jang, S. Kang et al., "Mesenchymal stem cellconditioned medium enhances osteogenic and chondrogenic differentiation of human embryonic stem cells and human induced pluripotent stem cells by mesodermal lineage induction," Tissue Engineering-Part A, vol. 20, no. 7-8, pp. 1306-1313, 2014.

[37] H. Arien-Zakay, A. Nagler, H. Galski, and P. Lazarovici, "Neuronal conditioning medium and nerve growth factor induce neuronal differentiation of collagen-adherent progenitors derived from human umbilical cord blood," Journal of Molecular Neuroscience, vol. 32, no. 3, pp. 179-191, 2007.

[38] J. S. Gill, A. E. Schenone, J. L. Podratz, and A. J. Windebank, "Autocrine regulation of neurite outgrowth from PC12 cells by nerve growth factor," Molecular Brain Research, vol. 57, no. 1, pp. 123-131, 1998.

[39] A. Krishna, M. Biryukov, C. Trefois et al., "Systems genomics evaluation of the SH-SY5Y neuroblastoma cell line as a model for Parkinson's disease," BMC Genomics, vol. 15, article 1154, 2014.

[40] M.-H. Yang, S.-S. Yuan, T.-W. Chung et al., "Characterization of silk fibroin modified surface: a proteomic view of cellular response proteins induced by biomaterials," BioMed Research International, vol. 2014, Article ID 209469, 13 pages, 2014. 
[41] M. H. Yang, S. S. Yuan, Y. L. Chen et al., "Mass spectrometry in clinical diagnosis: a preliminary application in tumor cellular proteomics for biomarker discovery," Journal of Analytical Bioanalytical Techniques, vol. S2, article 9, 2014.

[42] M.-H. Yang, S.-B. Jong, C.-Y. Lu et al., "Assessing the responses of cellular proteins induced by hyaluronic acid-modified surfaces utilizing a mass spectrometry-based profiling system: over-expression of CD36, CD44, CDK9, and PP2A," Analyst, vol. 137, no. 21, pp. 4921-4933, 2012.

[43] T.-W. Chung, Y.-C. Tyan, R.-H. Lee, and C.-W. Ho, "Determining early adhesion of cells on polysaccharides/PCL surfaces by a quartz crystal microbalance," Journal of Materials Science: Materials in Medicine, vol. 23, no. 12, pp. 3067-3073, 2012.

[44] B. Lu and C. E. Bishop, "Mouse GGN1 and GGN3, two germ cell-specific proteins from the single gene Ggn, interact with mouse POG and play a role in spermatogenesis," Journal of Biological Chemistry, vol. 278, no. 18, pp. 16289-16296, 2003.

[45] C. Cheyuo, W.-L. Yang, and P. Wang, "The critical role of adrenomedullin and its binding protein, AMBP-1, in neuroprotection," Biological Chemistry, vol. 393, no. 6, pp. 429-439, 2012.

[46] T. Koyama, T. Sakurai, A. Kamiyoshi, Y. Ichikawa-Shindo, H. Kawate, and T. Shindo, "Adrenomedullin-RAMP2 system in vascular endothelial cells," Journal of Atherosclerosis and Thrombosis, vol. 22, no. 7, pp. 647-653, 2015.

[47] J. M. Schumacher, K. Artzt, and R. E. Braun, "Spermatid perinuclear ribonucleic acid-binding protein binds microtubules in vitro and associates with abnormal manchettes in vivo in mice," Biology of Reproduction, vol. 59, no. 1, pp. 69-76, 1998.

[48] J. M. Schumacher, K. Lee, S. Edelhoff, and R. E. Braun, "Spnr, a murine RNA-binding protein that is localized to cytoplasmic microtubules," Journal of Cell Biology, vol. 129, no. 4, pp. 10231032, 1995.

[49] A. Pires-daSilva, K. Nayernia, W. Engel et al., "Mice deficient for spermatid perinuclear RNA-binding protein show neurologic, spermatogenic, and sperm morphological abnormalities," Developmental Biology, vol. 233, no. 2, pp. 319-328, 2001.

[50] K. L. Carraway III, J. L. Weber, M. J. Unger et al., "Neuregulin2, a new ligand of ErbB3/ErbB4-receptor tyrosine kinases," Nature, vol. 387, no. 6632, pp. 512-516, 1997.

[51] L. Wu, S. J. Walas, W. Leung, E. H. Lo, and J. Lok, "Neuregulin-1 and neurovascular protection," in Brain Neurotrauma: Molecular, Neuropsychological, and Rehabilitation Aspects, F. H. Kobeissy, Ed., pp. 561-568, CRC Press, Boca Raton, Fla, USA, 2015.

[52] L. Mei and W.-C. Xiong, "Neuregulin 1 in neural development, synaptic plasticity and schizophrenia," Nature Reviews Neuroscience, vol. 9, no. 6, pp. 437-452, 2008.

[53] E. S. Anton, H. T. Ghashghaei, J. L. Weber et al., "Receptor tyrosine kinase ErbB4 modulates neuroblast migration and placement in the adult forebrain," Nature Neuroscience, vol. 7, no. 12, pp. 1319-1328, 2004.

[54] S. Nataf, P. F. Stahel, N. Davoust, and S. R. Barnum, "Complement anaphylatoxin receptors on neurons: new tricks for old receptors?" Trends in Neurosciences, vol. 22, no. 9, pp. 397-402, 1999.

[55] H. Lian, L. Yang, A. Cole et al., "NFאB-activated astroglial release of complement C3 compromises neuronal morphology and function associated with Alzheimer's disease," Neuron, vol. 85, no. 1, pp. 101-116, 2015.

[56] M. H. Yang, R. R. Krishnamoorthy, S. B. Jong et al., "Protein profiling of human nonpigmented ciliary epithelium cell secretome: the differentiation factors characterization for retinal ganglion cell line," Journal of Biomedicine and Biotechnology, vol. 2011, Article ID 901329, 28 pages, 2011.

[57] S. A. Sullivan, L. K. Barthel, B. L. Largent, and P. A. Raymond, "A goldfish Notch-3 homologue is expressed in neurogenic regions of embryonic, adult, and regenerating brain and retina," Developmental Genetics, vol. 20, no. 3, pp. 208-223, 1997.

[58] Y. Qu, K. Sakamoto, S. Takeda, T. Kayano, M. Takagi, and K. Katsube, "Differential expression of notch genes in the neurogenesis of mouse embryos," Oral Medicine \& Pathology, vol. 3, no. 1, pp. 21-28, 1998.

[59] H.-Y. Zhou and S.-L. Huang, "Current development of the second generation of mTOR inhibitors as anticancer agents," Chinese Journal of Cancer, vol. 31, no. 1, pp. 8-18, 2012.

[60] K. Ohtsuka and T. Suzuki, "Roles of molecular chaperones in the nervous system," Brain Research Bulletin, vol. 53, no. 2, pp. 141-146, 2000.

[61] A. M. Gammazza, R. Colangeli, G. Orban et al., "Hsp60 response in experimental and human temporal lobe epilepsy," Scientific Reports, vol. 5, article 9434, 2015.

[62] M. J. Feng, L. Zhang, Z. Liu, P. Zhou, and X. Lu, "The expression and release of Hsp60 in 6-OHDA induced in vivo and in vitro models of Parkinson's disease," Neurochemical Research, vol. 38, no. 10, pp. 2180-2189, 2013.

[63] D. Magen, C. Georgopoulos, P. Bross et al., "Mitochondrial Hsp60 chaperonopathy causes an autosomal-recessive neurodegenerative disorder linked to brain hypomyelination and leukodystrophy," American Journal of Human Genetics, vol. 83, no. 1, pp. 30-42, 2008.

[64] J. M. Avis and P. R. Clarke, "Ran, a GTPase involved in nuclear processes: its regulators and effecters," Journal of Cell Science, vol. 109, pp. 2423-2427, 1996.

[65] R. Bernad, H. van der Velde, M. Fornerod, and H. Pickersgill, "Nup358/RanBP2 attaches to the nuclear pore complex via association with Nup88 and Nup214/CAN and plays a supporting role in CRM1-mediated nuclear protein export," Molecular and Cellular Biology, vol. 24, no. 6, pp. 2373-2384, 2004.

[66] H. Saitoh, R. Pu, M. Cavenagh, and M. Dasso, "RanBP2 associates with Ubc9p and a modified form of RanGAP1," Proceedings of the National Academy of Sciences of the United States of America, vol. 94, no. 8, pp. 3736-3741, 1997.

[67] A. Pichler, A. Gast, J. S. Seeler, A. Dejean, and F. Melchior, "The nucleoporin RanBP2 has SUMO1 E3 ligase activity," Cell, vol. 108, no. 1, pp. 109-120, 2002.

[68] H. Saitoh, M. D. Pizzi, and J. Wang, "Perturbation of SUMOlation enzyme Ubc9 by distinct domain within nucleoporin RanBP2/Nup358," Journal of Biological Chemistry, vol. 277, no. 7, pp. 4755-4763, 2002.

[69] K.-I. Cho, H. Yi, A. Yeh et al., "Haploinsufficiency of RanBP2 is neuroprotective against light-elicited and age-dependent degeneration of photoreceptor neurons," Cell Death and Differentiation, vol. 16, no. 2, pp. 287-297, 2009.

[70] K.-I. Cho, H. Yi, N. Tserentsoodol, K. Searle, and P. A. Ferreira, "Neuroprotection resulting from insufficiency of RANBP2 is associated with the modulation of protein and lipid homeostasis of functionally diverse but linked pathways in response to oxidative stress," DMM Disease Models and Mechanisms, vol. 3, no. 9-10, pp. 595-604, 2010.

[71] K.-I. Cho, K. Searle, M. Webb, H. Yi, and P. A. Ferreira, "Ranbp2 haploinsufficiency mediates distinct cellular and biochemical phenotypes in brain and retinal dopaminergic and glia cells 
elicited by the Parkinsonian neurotoxin, 1-methyl-4-phenyl1,2,3,6-tetrahydropyridine (MPTP)," Cellular and Molecular Life Sciences, vol. 69, no. 20, pp. 3511-3527, 2012.

[72] P. Castagnet, T. Mavlyutov, Y. Cai, F. Zhong, and P. Ferreira, "RPGRIP1s with distinct neuronal localization and biochemical properties associate selectively with RanBP2 in amacrine neurons," Human Molecular Genetics, vol. 12, no. 15, pp. 1847-1863, 2003.

[73] D. E. Neilson, M. D. Adams, C. M. D. Orr et al., "Infectiontriggered familial or recurrent cases of acute necrotizing encephalopathy caused by mutations in a component of the nuclear pore, RANBP2," American Journal of Human Genetics, vol. 84, no. 1, pp. 44-51, 2009.

[74] R. R. Singh, S. Sedani, M. Lim, E. Wassmer, and M. Absoud, "RANBP2 mutation and acute necrotizing encephalopathy: 2 cases and a literature review of the expanding clinicoradiological phenotype," European Journal of Paediatric Neurology, vol. 19, no. 2, pp. 106-113, 2015.

[75] T. Yamada, R. Sawada, and T. Tsuchiya, "The effect of sulfated hyaluronan on the morphological transformation and activity of cultured human astrocytes," Biomaterials, vol. 29, no. 26, pp. 3503-3513, 2008. 


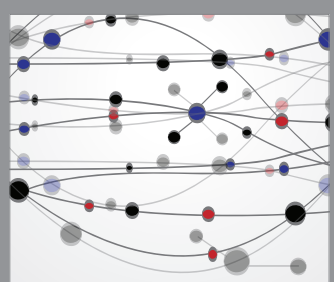

The Scientific World Journal
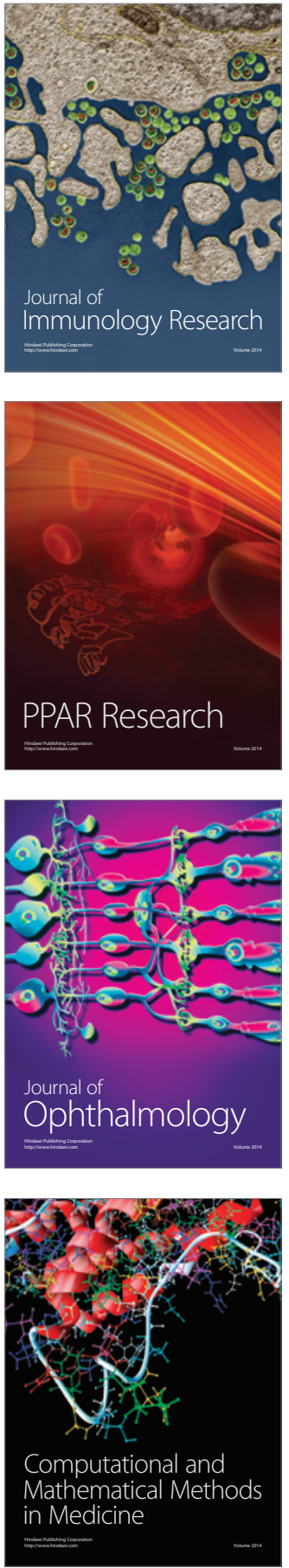

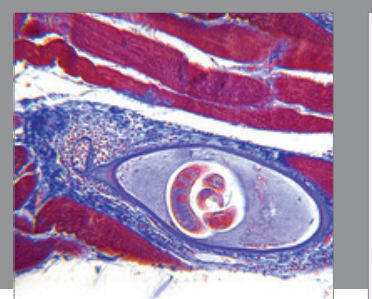

Gastroenterology Research and Practice

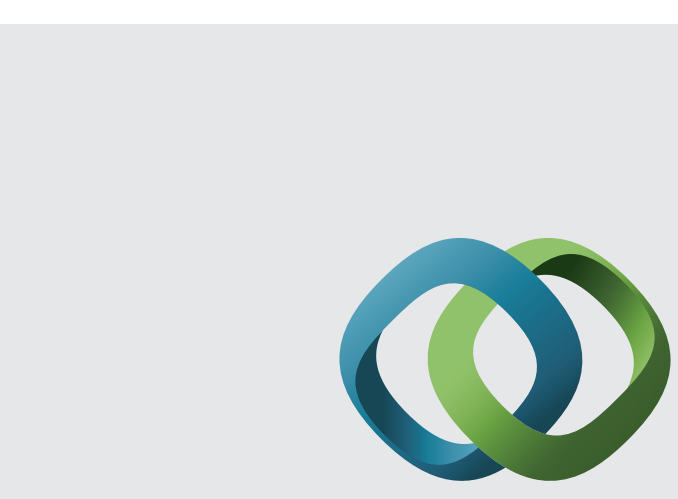

\section{Hindawi}

Submit your manuscripts at

http://www.hindawi.com
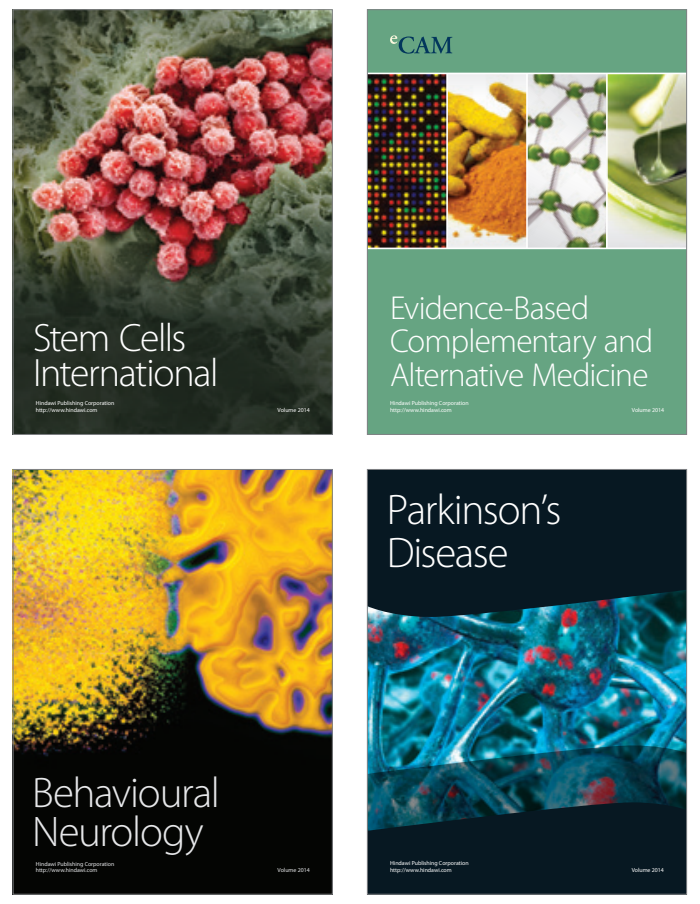
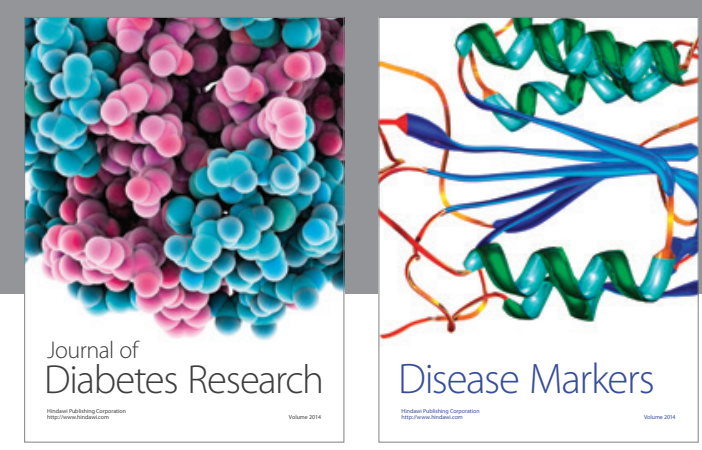

Disease Markers
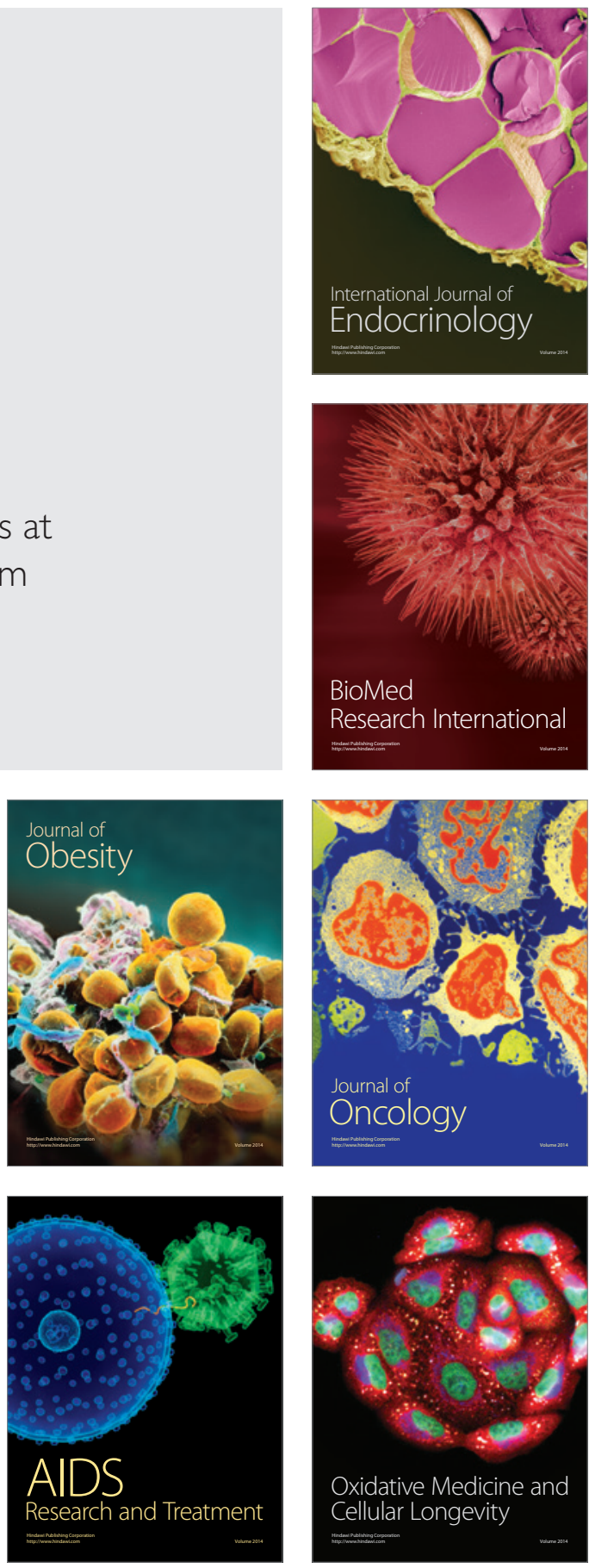